\title{
Victim precipitation: why we need to expand upon the theory
}

\begin{abstract}
Victim precipitation is a controversial theory asserting that victims sometimes initiate the actions which lead to their harm or loss. It is important to study because research shows that it happens with some frequency, and therefore cannot be ignored simply because it is distasteful. This paper examines a number of reasons why we should not only retain the theory of precipitation but expand upon it through more discourse and research. A thorough examination of the literature and research reveals more than enough evidence to show that precipitation is useful within the disciplines of criminology and victimology. Going beyond the often misplaced criticism of victim blaming, a better understanding of the role victims play in crime could help better tailor services for them in order to reduce victimisation or re-victimisation.
\end{abstract}

Keywords:victim, victimology, criminology, victims of crime, precipitation, victim precipitation, victim blaming
Volume 5 Issue 2 - 2017

\author{
Wayne Petherick \\ Faculty of Society and Design, Bond University, Australia
}

Correspondence: Wayne Petherick, Associate Professor of Criminology, Faculty of Society and Design, Bond University, Gold Coast, Australia, Tel 6175595 II24, Email wpetheri@staff. bond.edu.au

Received: July 14, 2017 | Published: July 18, 2017

\section{Introduction}

Victim precipitation was a term first used by Wolfgang to describe situations in which the victim was the initial aggressor in the action that led to their harm or loss. ${ }^{1}$ Victim precipitation existed not only in the research of Wolfgang but also in spirit in the early typologies of Mendelsohn (1956) such as the completely innocent victim (no precipitation) and the victim more guilty than the offender where one provokes another to commit a crime. Precipitation can also be seen in the typology of von $\mathrm{Hentig}^{2}$ in the tormentor, who precipitates his victimisation by torturing his family, and in Schafer's ${ }^{3} t y p o l o g y$ with provocative victims and explicitly with precipitative victims. The latter type is a direct acknowledgement that some victims have characteristics or do something that entices an offender to commit crimes against them and is more akin to what Siegel ${ }^{4}$ calls passive precipitation.

These early typologies of victimisation, in which precipitation played a part, were often developed by lawyers attempting to understand how much responsibility the victim carried relative to that of the offender. In some way, it could be said that these were attempts to, partially at least, mitigate the actions of the criminal and allow for some consideration in sentencing. Indeed, $\mathrm{Schafer}^{3}$ directly offers this as a justification for the development of his own typology: "although one might disagree with the idea that proposes to assess the victim's responsibility, this concept may operationally cover the pivotal issue in the criminal-victim relationship that, after all, is the critical problem of understanding and judging crime". These early attempts and their emphasis on assigning responsibility are no doubt instrumental in the negative stigma attached to the very idea of victim precipitation today, where any attempt to understand the role of the victim is met with ire or derision. This is especially true from victim advocates who see it as undermining victim status while simultaneously excusing the offender for the crime. As applied by this author and colleagues, nothing could be further from the truth.
While there may be a victim-offender duality or dyad that exists in theory, where victims are viewed as always good or virtuous and offenders as always bad or predatory, the reality of crime exists somewhere in the hazy middle. No doubt there are many cases where the crime would have occurred regardless of the victim's actions, but there are also many cases where the crime would not have occurred, at least at that time, if not for the actions of the victim. To ignore this is to ignore a reality of crime, thereby undermining attempts to understand it. Because of this, the author and colleagues believe that we should not ignore victim precipitation, no matter how distastefully it is viewed by some authors (see Eigenberg et al., ${ }^{5}$ who actually discuss precipitation in a chapter titled Victim Blaming).

Because it is a feature of crime, it is my contention that it should be studied further so that we can develop a better understanding of the types of precipitation that exist, and also the factors that contribute to precipitative actions. Only by doing so can be truly understand the context of crime and criminal and victim behaviour, and therefore hope to reduce or eliminate (at least certain types) of crime. Viewed in this way, understanding precipitation would be considered pro-victim as it works to reduce to the incidence, prevalence, and impact of crime upon them. Given this, the following reasons are proposed for not only retaining the theory as a useful construct in the understanding of crime, but also to expand upon it through more research and reinforcing the theoretical base on which it rests.

\section{Victim precipitation happens}

Perhaps the first reason we have for retaining and expanding upon victim precipitation is that it happens. The degree to which this is true differs according to the study, but those done show that it occurs with some frequency. These studies include Wolfgang (1958), Amir, ${ }^{6}$ Pesta, ${ }^{7}$ and McKinley (2015) among others. These studies demonstrate that victim precipitation is therefore significant and must be acknowledged. 


\section{Victim precipitation is not victim blaming}

Despite the protestations of some, victim precipitation has departed from its early bonds, and is no longer an attempt to understand what Schafer ${ }^{3}$ calls "functional responsibility". This alignment with victim blaming is not helped by some of the studies such as $\mathrm{Amir}^{6}$ which revolved around sexual assault where it is often viewed that a manner of dress or behavior is seen as a sexual invitation. Attempts have thus far been made to address this concern, ${ }^{8,9}$ redirecting inquiries about precipitation from any form of blame to attempts to understand the criminal event in its totality.

An example the author uses often is the negotiation that stalking victims often engage in to try and end harassment. They may make meetings with their pursuer to try and "reason" with them about how the stalking is negatively impacting them and how they would like it to stop. The stalker, inevitably with a self-interest outside of and beyond the victim's desires, sees these meetings as just another opportunity for contact. It could be said that the victim precipitated further stalking by demonstrating that if the stalker continue, the victim will make another meeting with them to plead their case. Nowhere here are we blaming the victim as they are simply doing what they think will work. But a threat manager on will view this as a behaviour worthy of change if the victim truly wants the stalking to stop.

\section{Assists in understanding the dynamics between victims and offenders}

This facet helps us to understand that some victims can also be offenders, and some offenders can also be victims (Muftić\& Hunt, 2013). Because of this, any attempt to understand crime will be incomplete without understanding the full gamut of behaviours engaged in by all parties, and any characterization of the offendervictim dyad as black and white will be largely incorrect.

\section{Providing a deeper understanding of victimization}

Studying precipitation allows us to understand more about how the victim and offender are connected. Whether compiling a victimology or doing a thorough analysis of a criminal event (such as an Applied Crime Analysis or ACA, see Petherick et al., ${ }^{9}$ every effort must be made to understand the breadth and depth of physical and emotional experiences of each party, along with how they perceived and responded to events, and how others responded to their responses, and so on

\section{Providing a deeper understanding of offending}

Though not trying to excuse the offender, an analysis of precipitation provides a full accounting of the offender's responsibility in the commission of a crime. This examination may help understand issues relating to offender motivation and intent, among other possible insights.

\section{Victim precipitation in legal proceedings}

Perhaps the most danger of aligning victim precipitation and victim blame comes in the form of legal attempts to understand victim and offender roles. Whether we view attempts to mitigate the offender's responsibility or culpability as victim blaming, the reality is that such examinations are allowable under the law. This may be in the form of the so-called partial defences, such as provocation, of the full defences, such as self defence. If there is a problem with doing this from the point of view of understanding the various roles in the crime, then it would be reasonable to assert that your problem is with the law, not with the theory of victim precipitation per se. While this may be a problem for some, the outcome of any cases will likely hang on a large number of factors, only one of which is any identified precipitation. What is more, it could be said that considering the actions of the victim is only fair, giving the common but-for argument used in legal discourse. That is, but for the actions of the victim, the offender wouldn't have acted in this way/the crime would not have occurred.

\section{Assists in understanding risk factors for recidivism and victimisation}

Studying precipitation helps understand risk factors related not only to the initial victimisation but also to possible re-victimisation. Any factors that contribute to becoming a victim can exist outside of the victim's conscious awareness and therefore outside of their immediate control. This means that those maladaptive behaviours which lead to crime are more likely to be repeated. Therefore, identifying and understanding the root cause of these can be useful in providing primary, secondary, and tertiary intervention so as to reduce or eliminate the harm or loss experienced by victims. Indeed much of the work done by the author in helping victims of stalking has been in demonstrating the role their own behaviour has played and how to change this so as to reduce or totally eliminate the intrusions.

\section{Conclusion}

Victim precipitation has been used in our understanding of victimisation for over sixty years or so now, during which time it has been studied and criticised. Research shows that precipitation occurs with some frequency, which one would consider enough of a reason to continue with study of the phenomenon. Critics, however, argue that precipitation is tantamount to victim blaming and that, at the very least, use of the term and the theory behind it should stop. The purpose of this article and the works done by this author and others is to show that victim precipitation is still useful in understanding crime, and that beyond concerns about blame, may actually provide a positive contribution to reducing crime and victimisation. At the very least we cannot profess to truly know what happened in a crime unless a full accounting of both the victim and offender behaviour has been undertaken. Like it or not, victim precipitation will provide part of this understanding.

\section{Acknowledgments}

I would like to thank Natasha Petroff, JuliJalil, and Claire Ferguson, fellow authors on the full paper for their assistance in bringing my ideas about victim precipitation to form.

\section{Conflicts of interest}

The author declares there are no conflicts of interest.

\section{References}

1. Petherick WA, Sinnamon GCB. Motivations: Victim and Offender perspectives. In: Petherick WA, editor. Profiling and serial crime: Theoretical and Practical Issues. 3rd edn. Anderson Publishing, USA. 2013;393-430.

2. Von Hentig H. The criminal and his victim: Studies in the sociobiology of crime. Yale University Press, USA. 1948;1-461. 
3. Schafer S. Victimology: The victim and his criminal. Reston Publishing Company, USA. 1968.

4. Siegel L, Joanne M Ziembo Vogl. Criminology: Theories, Patterns, and Typologies. 10th edn. Wadsworth Publishing Company, USA. 2010.

5. Eigenberg H, Garland T. Victim blaming. In: Moriarty LJ, editor. Controversies in Victimology, Anderson Publishing, USA. 2008;21-36.

6. Amir M. Victim precipitated forcible rape. The Journal of Criminal Law, Criminology, and Police Science. 1967;58(4):493-502.
7. Pesta R. Provocation and the point of no return: An analysis of victimprecipitated homicide. Youngstown State University, USA. 2011;1-67.

8. Ferguson C, Petherick WA, Turvey BE. Forensic victimology. In: Petherick WA, Turvey BE. edtors. Forensic Criminology, Academic Press, USA. 2010.

9. Petherick WA, Ferguson CE. Forensic victimology. In: Petherick WA, editor. Applied Crime Analysis: A Social Science Approach to Understanding Crime, Criminals, and Victims. 2015;148-171. 